\title{
Green Houses and Nursing Homes: Changes in Resident Function Over the Course of 1 Year - A Pilot Study
}

\author{
Daniela Costa, Rachel Moore, Rachael Stanzel, Chelsea Thornburg, Heather Braden* and Mansoo Ko \\ Department of Physical Therapy, USA
}

*Corresponding author: Heather Braden, Professor, Department of physical therapy, Angelo State University, USA

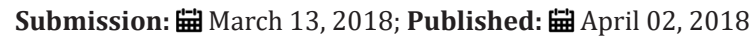

\begin{abstract}
Background and purpose: Seniors face difficult decisions if their physical and mental functioning begins to decline. Seniors may require assistance as they become elderly, but they never want to burden family members with that responsibility. Some choose to move to traditional nursing homes $(\mathrm{NH})$, and another option that is growing in demand is green houses (GH).Whether the elderly can safely maintain their movement ability over time in green houses has not been studied. The purpose of this study is to examine the changes in impairments and activity limitations in residents of green houses and nursing homes over the course of one year.
\end{abstract}

Participants: Of the 23 volunteer participants in this study over the age of 65,17 were residents of area nursing homes and 6 were residents of area green houses.

Methods: Participants completed a series of outcome measures including the Mini-Mental State Examination (MMSE), Manual Muscle Testing (MMT), Active Ankle Range of Motion (AROM), Handgrip Strength, Five Time Sit to Stand (5xSTS), Timed Up and Go (TUG), Gait Speed (GS) and Functional Independence Measure (FIM) scores.

Result: 15 completed the final data collection $(\mathrm{GH}=2, \mathrm{NH}=13)$. Before the final data collection, 4 participants from both the $\mathrm{NH}$ and the $\mathrm{GH}$ passed away equaling 8 total expired. Regarding impairments, the overall lower extremity strength of all surviving participants decreased from initial to final testing, with left knee extension strength and bilateral dorsiflexion strength being the two most distinct declines. Ankle range of motion (ROM) decreased for 14 out 15 surviving participants, with the exception of the D2 GH resident increasing right DF ROM by 1.5 degrees. The activity limitation changes included all participants of both groups performing slower on the TUG from initial to final testing with the $2 \mathrm{GH}$ residents performing 2-10 times slower than the average NH resident.

Discussion and conclusion: This study demonstrates that there are impairments and activity limitation measurements that can be used to assess change in function over the course of one year in green house $(\mathrm{GH})$ residents compared to traditional nursing home ( $\mathrm{NH}$ ) residents. Interventions provided by physical therapists for elderly residents at a green house or traditional nursing home facility can potentially slow the development of such impairments and activity limitations that may compromise longevity, independence and quality of life.

Keywords: Impairments; Activity limitations; Green houses; Senior living; Outcome measure

\section{Introduction}

Seniors living in long term care facilities, such as nursing homes $(\mathrm{NH})$ and green houses (GH), have multiple comorbidities often resulting in limited independence in functional mobility. Changes in residents who reside in nursing homes have been studied, but little evidence is available regarding green houses for senior living. One study found that $56 \%$ of $\mathrm{NH}$ residents fail to maintain function over 2 years in daily activities such as ambulation, transfers, and toileting. The strongest prognostic factors are decreased cognition, incontinence, and increased hospitalizations [1]. Another study found that $53 \%$ of residents died within 6 months and $65 \%$ died within one year of nursing home admission [2]. Current studies are lacking to identify quantitative data regarding function as it relates to mortality in $\mathrm{GH}$, however, studies overall support lower mortality rates.

In addition to cognition and activity declines that have been reported over time in nursing homes, falls are an additional debilitating factor. Falls are the leading cause of mortality and morbidity in the elderly and represent one of the most costly public health problems worldwide $[3,4]$. Studies have shown that $20-30 \%$ of people who fall suffer moderate to severe injuries that 
will greatly impact their functional mobility and independence [4]. About $30 \%$ of community-dwelling older adults fall at least once a year, with this percentage increasing to $43 \%$ for those people that reside in nursing homes. Approximately $50 \%$ of individuals over the age of 85 suffer from at least one fall per year [5]. While fall risk is multifactorial, reduced strength is most commonly associated with falls among nursing home residents [3,6]. As physical therapists, it is important to facilitate patient independence with mobility and ADLs to prevent functional decline, deconditioning and disability [6]. Other factors that play a role in fall risk are decreased gait speed, impaired cognitive ability and increased psychotropic drug prescriptions [7-9]. For example, residents with a scheduled prescription of psychotropics were associated with a three-fold increase in fall incidence [8]. Due to the prevalence of falls, it is important to identify fall risk-related factors to effectively design interventions that address this issue [3]. The number of falls that occurred during the current study were assessed along with changes in impairments and activity limitations, comparing $\mathrm{GH}$ versus NH residents.

This study specifically aimed to look at the difference in functional mobility in residents living in traditional NH vs. GH. The GH concept stems from the traditional nursing home model but differs by focusing more on patient centred care. The GH model was designed to alleviate the "three plagues" of nursing-home life-loneliness, boredom and helplessness [10]. Its core elements consist of nursing resident-directed care, architecture that reflects a family home, close relationships among staff and residents, staff empowerment, collaborative decision-making processes, and quality improvement efforts [10-12]. Studies have proven that GH elders are happier, healthier, and more willing to participate in social activities than traditional nursing home residents. Elders are also less likely to become hospitalized or to experience declines in activities of daily living. The net result is typically a decrease in mortality rate A standard GH has its own entrance and contains 6 to 12 residents per house with consistent assignment of the same staff for the resident each week. Each resident has his/her own bedroom and bathroom [10-13].

In traditional nursing homes, residents often share a bedroom and bathroom with at least one other resident [14]. The layout of the green houses mimic that of a traditional home which includes a communal living room, large dining room and an open kitchen [10-14]. The traditional nursing home components, such as a nurse station, long, multiple corridors, medication carts, and a paging system, are avoided in GH homes [11]. The green houses are run by certified nurse aides (CNAs) called Shahbazim, who are responsible for the communication between the residents and healthcare providers. Shahbazim have expanded universal roles such as preparing meals, shopping, activities, and housekeeping duties including cleaning and laundry. Three CNAs are typically assigned to each GH [10]. Studies have shown that GH caregivers experience less stress than caregivers in traditional nursing homes. A study identified a decreased turnover rate of CNAs in GHs (19\%) compared to nursing homes (50\%) in 2014
In traditional nursing homes, there is a decreased staff to resident ratio, diminishing capability of resident centered care. It can be argued that this system of fewer staff and more residents promotes "forced dependency" of NH residents in order to increase efficiency of the larger operation. An example of forced dependency is using a wheelchair for a resident that is a slow walker instead of encouraging independent standing mobility [10]. There are 242 GHs operating in 32 states, with 150 more under development [15-17]. In 2016, the average daily private-pay rates ranged from $\$ 433$ - \$495 according to one study completed in the north-eastern US whereas the national average was $\$ 225$ per day for a shared room and $\$ 253$ for a private room in a nursing home [15]. Fortytwo percent of green house residents are on Medicaid. Medicaid and Medicare reimburse along the same lines as a traditional nursing home. However, the states' Medicaid reimbursement rates do not take into account the cost of the extra square feet for individual bedrooms. Each facility determines its own private pay cost structure based on their local market, allowing for private-pay patients and other funding sources to compensate for those lowerincome residents [10-16].

Seniors who choose a green house as their residence aim to experience increased quality of life and functional status due to more independence and individualized care over traditional nursing homes [17-19]. However, if long term care residents in $\mathrm{NH}$ or GH experience a fall/adverse event and have a primary diagnosis of dementia, they have difficulty regaining function [20]. The purpose of this study was to assess changes in impairments and activity limitations over the course of a year that may be informative for establishing treatment plans by physical therapists who see residents in green houses and nursing homes.

\section{Methods}

\section{Design}

This study was approved by the Angelo State University Institutional Review Board. This was a retrospective observational study in which the authors aimed to utilize a regression analysis statistical design. This study aimed to assess changes in residents over the course of one year in GH and nursing homes. Predictor variables that were pertinent to $\mathrm{GH}$ and nursing home settings were determined prior to the study and then data was collected initially and again after one year. The authors completed a follow up study and expanded upon the work of Moyer, Gale, Severe, Braden, and Hasson (2017) [19]. The unique qualities in this study include functional outcomes of GH participants. In addition, rather than using the Mini Mental Status Examination (MMSE) score as exclusion criteria, as the prior study did, the MMSE was used to compare physical outcomes to mental strengths of the participants. Impairments and activity limitations were assessed as a means of determining safety risks involved in the resident's functional mobility. The numbers of falls in the six months prior to the study were documented at initial data collection. Information about each participant's fall history was gathered from the medical staff at their respective facility. Falls occurring during the course of the

How to cite this article: Costa, D., Moore, R., Stanzel, R., Thornburg, C., Braden, H., and Ko, M. Green Houses and Nursing Homes: Changes in Resident 
study were recorded at final data collection. Numbers of falls, in conjunction with other outcome measures, were to be analyzed for changes across both groups over a year.

\section{Participants}

A list of potential participants was acquired through the administrator of each facility. Participants and/or participant's caregivers were contacted by the researchers to acquire consent for the study. After consent forms were signed, the residents were then eligible to participate. Inclusion criteria were the following: age $>60$ years, ambulatory with or without assistive device for at least 24 feet, no hospital discharge within the last 6 weeks and able to follow 1 to 2 - step verbal commands. All participants were medically cleared by facility staff prior to testing.

\section{Procedures}

All participants were tested by the same examiner using the same methods from initial to final data collection within their own facility. The nursing staff at the facilities provided the medications taken by each participant from the medical record. Prior to testing, blood pressure and heart rate were taken. Next, the MMSE was administered to determine if mental status played a role in the participant's impairments and activity limitations. After completing the MMSE, the following measurements were taken in the respective order: 1) Manual Muscle Testing (MMT), 2) Active Ankle Range of Motion (AROM), 3) Handgrip Strength, 4) Five Time Sit to Stand (5xSTS), 5) Timed Up and Go (TUG), 6) Gait Speed (GS) and 7) Functional Independence Measure (FIM). Following testing, each participant was assigned a Functional Independence Measure (FIM) score for ambulation by the tester based upon FIM definitions. An assistive device was allowed throughout all testing sessions if needed, and type of assistive device was recorded. Verbal instructions were given to participants for each test, and the researcher was available for additional assistance as needed.

\section{Clinical Impairment Outcomes}

Handheld dynamometry is a tool that is widely used to assess for lower extremity muscle strength. A microFet 2 dynamometer was used to measure participants' strength in pounds. Seated ankle dorsiflexion, ankle plantar flexion, knee flexion, knee extension, hip flexion, hip abduction, hip adduction and hip extension were assessed in the respective order bilaterally. Participants were required to perform two trials for each of the above muscle testing. The following cues were given during MMT, “Don't let me move you "It has been proven that the elderly who have poor muscle strength could experience more falls, limiting their everyday activities and mobility [20]. Another study concluded that lower extremity force production was lower in subjects reporting falls and that ankle dorsiflexion force predicted fall status [21]. Ankle plantar flexion strength has specifically been associated with increased balance and stability in the elderly [22].

Maintaining appropriate balance is crucial to preventing falls in the elderly. A decrease in flexibility and strength results in a decreased ability of recovering from perturbations, potentially causing a fall. Because of the reasons previously discussed, active range of motion was tested in the ankle dorsiflexors and ankle plantarflexors [23]. A standard large goniometer was used to assess active range of motion in the ankle. The goniometer was set-up as follows: the axis at the lateral malleoli, moveable arm at the fifth metatarsal and the stationary arm at the midline of the fibula.

Decreased grip force production is associated with an increased likelihood of falls and mortality risk [24,25]. In addition, grip strength testing is a useful tool to identify persons at risk of mobility limitations [26]. While grip strength is widely used as a predictor of falls, it is recently being used as an indicator of declining health [27]. A Jamar dynamometer, secured on the second setting, was used and hand strength was measured in pounds. Participants were asked to perform this test twice in each hand. The verbal instruction given was, "Squeeze this as hard as you can".

\section{Activity Limitation Outcomes}

The 5xSTS test is a valid measure of dynamic balance and functional mobility in older adults [28]. This assessment is an effective fall risk screening tool in participants suffering from lower limb arthritis [29]. Inability to complete 5xSTS was a marginal predictor of falls and a significant predictor of ADL and IADL disability [30]. The high ICC (0.95) and low SEM (0.9 seconds) suggest excellent relative and absolute reliability along with reproducibility in older adults [28]. Participants were asked to sit in a chair, stand up and sit back down five times consecutively. The directions given to the participants were, "When I say go, I want you to stand up and sit down five times. Use the armrests as needed". The time to complete the test was measured in seconds and participants performed two trials. One trial was performed prior to the TUG and gait speed testing. The last trial was performed after all other testing was complete.

The TUG is a commonly used screening tool that assists clinicians in determining fall risk in patients [31]. While some research suggests that the turning components involved in the TUG provide the patient a more complex task to complete, other research suggests that the TUG has a limited ability to predict falls in the elderly and should not be used in isolation [32]. This is why the TUG was used in addition to other activity based outcome measures such as gait speed and five times sit to stand. Each participant completed one trial of the TUG test. The participant began by sitting in a chair and was then asked to stand up and walk three meters (10 feet), turn around, walk and sit back in the chair. Specific instructions given were, "When I say go, I want you to stand up from this chair, walk to where she (other researcher) is standing, walk back and sit down in this same chair". The TUG test has been found to be more accurate at ruling in than ruling out individuals that are at high fall risk with a specificity of 0.74 and sensitivity of 0.31 [31].

Gait speed is an important measure in comprehensive geriatric assessment and has been described as the sixth vital sign [33]. A combination of history of falls and gait speed is a simple and effective tool in risk assessment of falls and physical function among the elderly [34]. An average speed of less than $0.5 \mathrm{~m} / \mathrm{sec}$ 
was associated with an increased risk of falls. For this study, gait speed was assessed with a modified version of the ten meter walk test. The participants performed a six meter (18 feet) walk test and were allowed to use assistive devices. Before testing began, the participants were instructed to walk at a self-selected pace until told to stop. Specific instructions given were, "When I say go, you are going to walk forward down this hallway. Keep going until I say stop". Participants were allowed a one meter (3 feet) acceleration and deceleration zone to allow for normal acceleration and deceleration to occur with a four meter (13 feet) test zone in between. The six meter walk test has excellent test-retest and inter-rater reliability with an ICC $=0.97$ and 0.99 , respectively [35]. The validity of this test has been primarily assessed in community dwelling populations [19].

\section{Statistical Analysis}

Due to the high attrition rate $(24 \%$ in $\mathrm{NH}$ and $67 \%$ in $\mathrm{GH}$ ), the researchers identified the need to use descriptive statistics to compare initial data of GH participants who completed the study to GH participants who expired after the initial data was gathered. Descriptive statistics were also utilized in identifying categorical data changes that took place longitudinally in surviving $\mathrm{GH}$ and $\mathrm{NH}$ participants.

\section{Result}

Of the 23 participants in this study, 17 were residents of area nursing homes and 6 were residents of area green houses. A total of 15 completed the final data collection $(\mathrm{GH}=2, \mathrm{NH}=13)$. Before the final data collection, 4 participants from both the $\mathrm{NH}$ and the $\mathrm{GH}$ passed away equaling 8 total expired. The current study aimed to explore the effects of seniors residing in green houses over a oneyear period as compared to traditional nursing home residents. The demographic information of the two surviving GH participants can be found in (Table 1) as well as the average information for the $\mathrm{NH}$ participant group. The results of the $\mathrm{GH}$ versus $\mathrm{NH}$ residents are presented in three parts:

Table 1: Profiles for the Research Participants Completing the Study.

\begin{tabular}{|c|c|c|c|c|c|c|}
\hline Subject ID & Age & Gender & Weight (lb) & MMSE (I)/(F) & Dominance & Ethnicity \\
\hline D1 & 98 & M & 192 & $19 / 19$ & Right & Caucasian \\
\hline D2 & 95 & F & 101 & $23 / 17$ & Right & Caucasian \\
\hline NH Mean & 88 & M/F & 170 & $24 / 21$ & Caucasian \\
\hline
\end{tabular}

MMSE = Mini Mental State Examination $(\max$ scored 30). $(\mathrm{I})$ = initial, $(\mathrm{F})$ = final NH Mean Code: Surviving Nursing Home Participants. D Subject Code: Surviving Green house Participants.

Table 2: Relevant Participant Outcomes.

\begin{tabular}{|c|c|c|c|c|c|c|c|}
\hline & \multicolumn{2}{|c|}{ D1 GH Participant } & \multicolumn{2}{|c|}{ D2 GH Participant } & \multirow{2}{*}{$\begin{array}{c}\text { GH Group } \\
\text { Mean, Expired }\end{array}$} & \multicolumn{2}{|c|}{ NH Group Mean, Survivors } \\
\hline & Initial & Final & Initial & Final & & Initial & Final \\
\hline Medications & 10 & 17 & 10 & 14 & $18.0( \pm 3.74)$ & $11.07( \pm 6.29)$ & $12.07( \pm 5.43)$ \\
\hline Falls & 0 & 0 & 0 & 2 & $2.50( \pm 0.50)$ & $.08( \pm .27)$ & $.77( \pm 1.12)$ \\
\hline DF strength (kg), R & 17.7 & 9.9 & 5.8 & 4.9 & $17.7( \pm 7.44)$ & $19.92( \pm 7.86)$ & $10.38( \pm 3.87)$ \\
\hline DF strength (kg), L & 19.5 & 9.8 & 6.8 & 4.9 & $13.78( \pm 3.07)$ & $19.92( \pm 8.54)$ & $10.05( \pm 3.08)$ \\
\hline Knee ext (kg), R & 20 & 11.9 & 6.8 & 4.8 & $16.38( \pm 7.54)$ & $18.9( \pm 7.19)$ & $11.65( \pm 5.12)$ \\
\hline Knee ext (kg), L & 22.8 & 12 & 6.5 & 3.2 & $14.95( \pm 7.87)$ & $20.05( \pm 7.55)$ & $11.99( \pm 5.61)$ \\
\hline Hip ext strength (kg), R & 13.1 & 6.2 & 6.7 & 2.4 & $15.93( \pm 8.28)$ & $16.43( \pm 8.00)$ & $9.62( \pm 6.60)$ \\
\hline Hip ext strength (kg), L & 12.6 & 7.8 & 6.3 & 3.4 & $14.6( \pm 6.79)$ & $16.17( \pm 8.80)$ & $8.66( \pm 5.15)$ \\
\hline Ankle DF ROM (d), R & 14.5 & -1 & -10 & -8.5 & $8.38( \pm 2.29)$ & $7.19( \pm 8.16)$ & $3.69( \pm 7.67)$ \\
\hline Ankle DF ROM (d), L & -9.5 & -0.5 & 6.5 & -3 & $7.87( \pm 6.30)$ & $8.46( \pm 6.68)$ & $4.73( \pm 6.91)$ \\
\hline Grip strength (lb), R & 27.5 & 25 & 4.4 & 3.4 & $19.08( \pm 6.77)$ & $34.72( \pm 17.20)$ & $31.42( \pm 15.48)$ \\
\hline Gait Speed (m/sec) & 27.5 & 0.51 & 0.77 & 0.35 & $0.43( \pm 1.19)$ & $0.56( \pm .17)$ & $0.51( \pm .23)$ \\
\hline 5x Sit To Stand (sec) & $\wedge$ & $\wedge$ & 23.2 & 55.6 & $42.93( \pm 39.78)$ & $25.7( \pm 14.37)$ & $24.55( \pm 12.19)$ \\
\hline Timed Up and Go (sec) & 29.5 & 34.6 & 20.3 & 49.8 & $38.63( \pm 17.72)$ & $29.2( \pm 12.36)$ & $31.74( \pm 17.40)$ \\
\hline
\end{tabular}

$\wedge=$ participant declined to participate in this activity.

A. individual data of the two surviving GH participants,

B. average data of the $\mathrm{GH}$ residents who expired prior to the final year of data collection, and

C. average data of the surviving NH resident group. Relevant outcomes for the groups listed above can be found in (Table 2) below. 


\section{Demographic Outcomes}

On average, the GH residents were at least 7 years older in age and presented with decreased MMSE scores compared to the average $\mathrm{NH}$ resident Of the $13 \mathrm{NH}$ residents included in the study, 8 were females and 5 were males leaving the female to male ratio for the entire study at 3:2. One NH resident was of Hispanic ethnicity, but due to the geographic location that the study took place in, 14 of the 15 total surviving participants were of Caucasian ethnicity.

\section{Impairment Outcomes}

As depicted above, the number of falls increased for both the D2 GH participant and the average of the 13 surviving NH residents between initial and final data collection. The number of medications also increased for all surviving participants throughout this time period. Interestingly, the $2 \mathrm{GH}$ residents showed a 4-7 times greater increase in number of medications over the one year period as compared to the average NH resident. Impairment level changes recorded in this study included strength and range of motion. Grip strength decreased for $1 \mathrm{GH}$ participant from initial to final, stayed the same for $1 \mathrm{GH}$ participant, and decreased on average for the NH group. The overall lower extremity strength of all surviving participants decreased from initial to final testing, with left knee extension strength and bilateral dorsiflexion strength being the two most distinct declines. Ankle range of motion (ROM) decreased for 14 out 15 surviving participants, with the exception of the D2 GH resident increasing right DF ROM by 1.5 degrees.

\section{Activity Limitations}

The activity limitations recorded in the current study were gait speed, 5xSTS Test, and Timed Up and Go (TUG) Test. Gait speed was found to be slower for the D2 GH participant and also for the $\mathrm{NH}$ group on average from initial to final measurements. However, gait speed improved for the D1 GH participant over the one year time frame by $0.07 \mathrm{~m} / \mathrm{s}$. The D2 GH participant performed the $5 \mathrm{xSTS}$ test much slower compared to the NH group who performed the same test faster at final testing. Participant D1 declined to participate in this specific test at both initial and final testing due to health conditions and safety. All participants included in both groups performed slower on the Timed Up and Go Test from initial to final testing with the $2 \mathrm{GH}$ residents performing 2-10 times slower than the average $\mathrm{NH}$ resident.

\section{Discussion}

The purpose of this study was to identify changes in impairments and activity limitations for residents of green houses and nursing homes over the span of one year. It is important that health care providers, caregivers, and researchers in geriatric care have access to the results of this study to enable follow up studies to take place. This study produced some risk factors for mortality that the researchers did not expect. When observing the data of the residents in the green houses that passed away, this group had a high number of falls, low grip strength, and slow activity limitation scores at initial assessment (Table 2, GH Group Mean, Expired, Initial Data). Specifically, the high number of falls and poor grip strength look to be strong predictors to determine mortality in the green houses. Future studies can provide more participants to confirm this observation.

It was determined through this study that on average the When screening for people to participate in this study, many green house residents did not meet the inclusion criteria secondary to decreased mobility or recent hospitalization (Tables 1 and 2). When searching for residents to participate in this study, the green house facilities many residents that did not meet the inclusion criteria secondary to decreased mobility or recent hospitalization. This limited the ability to include a symmetrical number of participants from both the GH and $\mathrm{NH}$ facilities.

There were many limitations found throughout the course of this study. The most significant limitation was the high attrition rate secondary to the natural cause of death in 8 total participants. This attrition rate required the original statistical design to be adapted to descriptive statistics as a pilot study for future studies to build upon. Demographics were also a limitation considering the majority of the study participants were Caucasian, which does not accurately represent all seniors in long term facilities. This could be a result of the research being limited to a single city located in West Texas. Location played a large role in providing appropriate participants meeting the inclusion criteria resulting in an asymmetrical sample size between $\mathrm{NH}$ and $\mathrm{GH}$ residents. The location of the study provided a larger selection of nursing home as compared to only 2 green house locations available. Because of this, the researchers were able to include 17 nursing home residents versus the 6 green house residents at initial data collection, limiting the researchers to a small sample size. Another limitation included the decline in cognitive status in the majority of the participants resulting in difficulty performing instructed tasks. Also, some data points were unable to be collected from a few participants due to declination of that particular test. Overall, compliance with the testing protocols of this study was successful (Table 3).

Table 3: Participant Final Minus Initial Change Score.

\begin{tabular}{|c|c|c|c|c|}
\hline & $\begin{array}{c}\text { D1 GH } \\
\text { Participant }\end{array}$ & $\begin{array}{c}\text { D2 GH } \\
\text { Participant, }\end{array}$ & \multicolumn{2}{|c|}{ Group Mean, Survivors } \\
\hline & $\begin{array}{c}\text { Change } \\
\text { Score }\end{array}$ & $\begin{array}{c}\text { Change } \\
\text { Score }\end{array}$ & $\begin{array}{c}\text { Change } \\
\text { Score }\end{array}$ & SD \\
\hline Medications & 7 & 4 & 1 & 5 \\
\hline Falls & 0 & 2 & 0.69 & 1.2 \\
\hline MMSE & 0 & 6 & 3.4 & 4.3 \\
\hline $\begin{array}{l}\text { DF strength } \\
\text { (kg), R }\end{array}$ & -7.8 & -0.9 & -9.5 & 7.4 \\
\hline $\begin{array}{l}\text { DF strength } \\
\text { (kg), L }\end{array}$ & -9.7 & -1.9 & -9.4 & 7.4 \\
\hline $\begin{array}{c}\text { Knee ext } \\
\text { (kg), R }\end{array}$ & -8.1 & -2 & -7.3 & 4.6 \\
\hline $\begin{array}{l}\text { Knee ext } \\
\text { (kg), L }\end{array}$ & -10.8 & -3.3 & -8.1 & 6.8 \\
\hline $\begin{array}{c}\text { Hip ext } \\
\text { strength } \\
\text { (kg), R }\end{array}$ & -6.9 & -4.3 & -6.5 & 4.4 \\
\hline
\end{tabular}




\begin{tabular}{|c|c|c|c|c|}
\hline $\begin{array}{c}\text { Hip ext } \\
\text { strength } \\
\text { (kg), L }\end{array}$ & -4.8 & -2.9 & -6.9 & 6.7 \\
\hline $\begin{array}{c}\text { Ankle DF } \\
\text { ROM (d), R }\end{array}$ & -13.5 & -2 & -3.5 & 8.5 \\
\hline $\begin{array}{c}\text { Ankle DF } \\
\text { ROM (d), L }\end{array}$ & 6.5 & -9.5 & -4.8 & 5.6 \\
\hline $\begin{array}{c}\text { Grip } \\
\text { strength } \\
\text { (lb), R }\end{array}$ & -2.5 & -1 & -3.3 & 8.5 \\
\hline $\begin{array}{c}\text { Gait Speed } \\
\text { (m/sec) }\end{array}$ & 0.07 & -0.4 & -0.1 & 0.2 \\
\hline $\begin{array}{c}5 x \text { Sit To } \\
\text { Stand (sec) }\end{array}$ & 1 & 0.2 & 0.2 & 13.8 \\
\hline $\begin{array}{c}\text { Timed Up } \\
\text { and Go (sec) }\end{array}$ & 5.1 & 29.5 & 2.98 & 17.1 \\
\hline
\end{tabular}

2. Kelly A, Conell Price J, Covinsky K, Cenzer IS, Chang A, et al. (2010) Length of stay for older adults residing in nursing homes at the end of life. J Am Geriatr Soc 58(9): 1701-1706.

3. Barbosa FA, Pozo Cruz B, Poso Cruz J, Alfonso R, Corrales B (2016) Factors associated with the risk of falls of nursing home residents aged 80 or older. Association of Rehabilitation Nurses 41(1): 16-25.

4. Harnish A, Dieter W, Crawford A, Shubert TE (2016) Effects of evidencebased fall reduction programing on the functional wellness of older adults in a senior living community: a clinical case study. Frontiers in Public Health 4: 262.

5. Borowicz A, Zasadzka E, Gaczkowska A, Gawłowska O, Pawlaczyk M (2016) Assessing gait and balance impairment in elderly residents of nursing homes. J Phys Ther Sci 28(9): 2486-2490.

6. Powell B, Tazamal M, Buhr G, Powell B (2016) Increasing mobility in the nursing home through implementation of a restorative program. Journal of the American Medical Directors Association 17(3): B18.

7. Allali G, Launay CP, Blumen HM, Callisaya ML, De Cock AM et al. (2016) Falls cognitive impairment and gait performance: results from the good initiative. J Am Med Dir Assoc 18(4): 335-340.

above, the results of this study are not appropriate to provide an accurate clinical application to current individuals residing in nursing homes and green houses. However, the results can identify opportunities for a stronger research design in the future and provide a good starting point for researchers to build upon. This can be done by acquiring a larger sample size, smaller attrition rate, and improved selection of facilities which may be found in larger cities. Some ideas for future studies include: the functional decline in memory care units versus nursing homes, mental status in relation to fall risk, or how diagnoses and comorbidities can relate to change in functional status over a certain period of time.

\section{Conclusion}

Research has shown that a decrease in function has presented with prognostic factors such as decreased cognition and incontinence, increased hospitalizations, falls, psychotropic drug prescriptions, and decreased gait speed. This study demonstrates that there are impairments and activity limitation measurements that can be used to assess the change in function over the course of one year in green house $(\mathrm{GH})$ residents compared to traditional nursing home $(\mathrm{NH})$ residents. As geriatric clinicians, it is important to facilitate patient independence with mobility and ADLs to prevent functional decline, deconditioning and disability. Interventions provided by physical therapists for residents at a green house or traditional nursing home facility can potentially slow the development of impairments and activity limitations that may compromise longevity, independence and quality of life.

\section{Acknowledgement}

We would like to thank the green houses and nursing homes staff and families for making this study possible. We would like to thank Dr. Lee Atkins for his guidance and knowledge regarding data presentation and analysis.

\section{References}

1. Jerez Roig J, Lidiane Maria de Brito Macedo Ferreira, Araújo JRTde, Lima KC (2017) Functional decline in nursinghome residents: Aprognosticstudy. PLoS ONE 12(5): e0177353.

8. Cox CA, Jaarsveld HJV, Houterman S, van der Stegen JC, Wasylewicz AT et al. (2016) Psychotropic drug prescription and the risk of falls in nursing home residents. J Am Med Dir Assoc 17(12): 1089-1093.

9. Seijo Martinez M, Cancela JM, Ayán C, Varela S, Vila H (2016) Influence of cognitive impairment on fall risk among elderly nursing home residents. Int Psychogeriatr 28(12): 1975-1987.

10. Garland SB (2016) A new model for nursing home care. Kiplingers Retirement Report: Your Guide to a Richer Retirement 23(4): 2-5.

11. Yoon JY, Brown RL, Bowers BJ, Sharkey SS, Horn SD (2016) The effects of the green house nursing home model on adl function trajectory: a retrospective longitudinal study. Int J Nurs Stud 53: 238-247.

12. Afendulis CC, Caudry DJ, O'malley AJ, Kemper P, Grabowski DC (2016) Green House Adoption and Nursing Home Quality. Health Serv Res 51(Suppl 1): 454-474.

13. Fishman NW, Lowe JI, Ryan SF (2016) Promoting an Alternative to Traditional Nursing Home Care: Evaluating the Green House Small Home Model. An Introduction from the Funders and the Green House Project. Health Serv Res 51(Suppl 1): 344-351.

14. Asghar N (2016) Transitioning into a 'Green house' Nursing Home: A Resident and Shabazism Perspective: 1-32.

15. (2017) Nursing Home Care Costs Are Only Slightly Higher in 2016. Elder LawAnswers.

16. (2017) The new standard in long-term and post-acute care, with national brand power, higher measurable quality outcomes, consumer demand, and caregiver satisfaction. Welcome Home - The Green House Project.

17. Span P (2018) A Better Kind of Nursing Home. New York, USA.

18. Aizen E (2015) Falls in patients with dementia. Harefuah 154(5): 323 326.

19. Mover HS, Gale J, Severe S, Braden HJ, Hasson S (2017) Outcome measures correlated to falls in nursing home residents - A pilot study. Physiother Theory Pract 33(9): 725-732.

20. Cho KH, Bok SK, Kim Y-J, Hwang SL (2012) Effect of lower limb strength on falls and balance of the elderly. Ann Rehabil Med 36(3): 386-393.

21. Daubney ME, Culham EG (1999) Lower-extremity muscle force and balance performance in adults aged 65 years and older. Phys Ther 79(12): 1177-1185.

22. Bok S-K, Lee TH, Lee SS (2013) The Effects of Changes of Ankle Strength and Range of Motion According to Aging on Balance. Ann Rehabil Med 37(1): 10-16. 
23. Chiacchiero M, Dresely B, Silva U, Delosreyes R, Vorik B (2010) The relationship between range of movement, flexibility, and balance in the elderly. Topics in Geriatric Rehabilitation 26(2): 148-155.

24. Reis P, Moro A, Bins V, Fernandes C, Vilagra J (2012) Universal design and accessibility: an approach of the influence of muscle strength loss in the risk of falls in the elderly. Work 41: 374-379.

25. Rolland Y, Lauwers Cances V, Cesari M, Vellas B, Pahor M, et al. (2006) Physical Performance Measures as Predictors of Mortality in a Cohort of Community-dwelling Older French Women. Eur J Epidemiol 21(2): 113-122.

26. Sallinen J, Stenholm S, Rantanen T, Heliövaara M, Sainio P, et al. (2010) Hand Grip Strength Cut Points to Screen Older Persons at Risk for Mobility Limitation. J Am Geriatr Soc 58(9): 1721-1726.

27. Xue QL (2011) Prediction of Risk of Falling, Physical Disability, and Frailty by Rate of Decline in Grip Strength: The Women's Health and Aging Study. Arch Intern Med 171(12): 1119-1121.

28. Goldberg A, Chavis M, Watkins J, Wilson T (2012) The five times-sit-tostand test: validity, reliability and detectable change in older females. Aging Clin Exp Res 24(4): 339-344.

29. Reider N, Gaul C (2016) Fall risk screening in the elderly: A comparison of the minimal chair height standing ability test and 5-repetition sit-tostand test. Arch Gerontol Geriatr 65: 133-139.
30. Zhang F, Ferrucci L, Culham E, Metter EJ, Guralnik J, et al. (2013) Performance on five times sit-to-stand task as a predictor of subsequent falls and disability in older persons. J Aging Health 25(3): 478-492.

31. Herman T, Giladi N, Hausdorff JM (2011) Properties of the 'timed up and go' test: more than meets the eye. Gerontology 57(3): 203-210.

32. Barry E, Galvin R, Keogh C, Horgan F, Fahey T (2014) Is the timed up and go test a useful predictor of risk of falls in community dwelling older adults: a systematic review and meta- analysis. BMC Geriatr 14: 14

33. Peel NM, Kuys SS, Klein K (2012) Gait speed as a measure in geriatric assessment in clinical settings: a systematic review. J Gerontol A Biol Sci Med Sci 68(1): 39-46.

34. Liang CK, Chou MY, Peng LN, Liao MC, Chu CL, et al. (2014) Gait speed and risk assessment for falls among men aged 80 years and older: A prospective cohort study in Taiwan. European Geriatric Medicine 5(5): 298-302.

35. Mendoza C, Garcia J, Ferrer A, Martinez M (2010) Evaluation of walking speed tests as a measurement of functional limitations in elderly people: A structured review. International Journal of Clinical and Health Psychology 10(2): 359-378.
Creative Commons Attribution 4.0 International License

For possible submissions Click Here

\section{Submit Article}

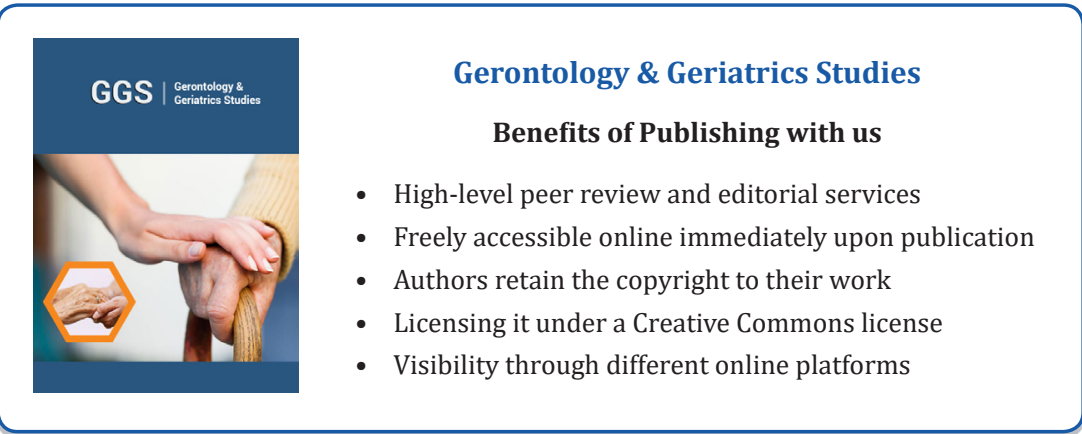

